\title{
Les origines du populisme : enquête sur un schisme politique et social
}

\author{
Yann Algan, Elizabeth Beasley, Daniel Cohen y Martial Foucault \\ París: Seuil et la République des Idées. 2019. 218 páginas.
}

Agustín De Marco

DOI: https://doi.org/10.46468/rsaap.14.1.R4

"Un fantasma recorre Occidente: el populismo". Los autores no escatiman epítetos al momento de dar cuenta de la prosperidad de dicho fenómeno en Estados Unidos, Reino Unido, Alemania, Austria, Polonia y Hungría, entre otros países. Sostienen, a su vez, que ya sea de izquierda o derecha, el aumento de fuerzas "antisistema" se halla íntimamente ligado al deterioro de las condiciones vida de las clases medias y populares, golpeadas por la inseguridad económica y la profundización de las desigualdades, particularmente luego de la crisis económica que azotó Europa en el año 2008.

Ante este nuevo escenario económico-cultural, tanto la izquierda como la derecha asisten a un desmoronamiento de su programática por causa del alza populista. De este modo, explican, el eje izquierda-derecha se actualiza a partir de una nueva configuración del electorado, allí donde la oposición tradicional terminó por ser indiferente a la geografía social.

A causa de ello, y a los fines de evitar toda ambigüedad, los autores utilizan dos expresiones distintas: la "izquierda radical" y la "derecha populista”, dos fuerzas unidas en su crítica al sistema, aunque profundamente opuestas en términos de valores y de plataformas políticas y económicas. Las dos se nutren de los programas tradicionales de la izquierda y la derecha, respectivamente. Redundan en su caracte- rización de la "izquierda radical" y la "derecha populista" en tanto fuerzas antisistema opuestas al Estado y a las élites, reservando el término "populista" a esta última, la cual agrupa la facción autoritaria y antiinmigrantes de dicho electorado.

El Capítulo I, “Tres crisis”, enmarca la subida del populismo en un contexto de crisis política, económica y cultural. La primera de estas crisis abreva en la desconfianza hacia las instituciones políticas nacionales y supranacionales, lo cual lleva a los votantes a agruparse en torno a las fuerzas "antisistema": la izquierda radical y la derecha populista. Esta crisis halla su eco en el fuerte resentimiento de las clases populares hacia los desajustes económicos, así como en la incapacidad de sus gobernantes para dar una solución a dichas problemáticas. Tanto las transformaciones económicas a largo plazo, como el shock brutal de la crisis financiera son esenciales para comprender el aumento de las fuerzas antisistema. Esta progresión de la radicalidad política traduce la pérdida de confianza de las poblaciones más vulnerables a los riesgos económicos en la capacidad del "sistema" para protegerlos. La crisis cultural viene dada por la hostilidad de la "derecha populista" hacia los inmigrantes, su fascinación por los valores autoritarios y un conservadurismo social de tenor nacionalista. Los autores se refieren a la avanzada antiliberal en 
términos de valores y de derechos sociales como "la sorpresa política más espectacular del período reciente". Tiene lugar, así, una paradoja central que ocupa a una sociedad que se creía más tolerante y, de repente, se ve tentada por valores profundamente antiliberales.

El Capítulo II, "La elección presidencial francesa de 2017", expone el caso francés como un punto culminante en la crisis del eje izquierda-derecha, el cual dominó el tablero político desde finales de la segunda guerra mundial. Tanto Macron como Le Pen sacaron provecho de una situación atípica: por primera vez desde la creación de la V República, ninguno de los partidos tradicionales de la izquierda y de la derecha logró llevar un candidato a segunda vuelta. A diferencia de Le Pen, cuyo ascenso había sido previsto por las encuestas, la aparición en escena de Emmanuel Macron fue totalmente imprevisible: sin partido ni pasado político, logró crear un bloque de centro, arrastrando un enorme caudal de votos de la centroizquierda. Los autores aseguran, así, que el eje izquierda-derecha se actualiza en función de la contienda de 2017 bajo el rótulo de "ganadoresperdedores", que opone a Le Pen contra Macron, respectivamente.

El Capítulo III, "Individuos y clases sociales", indaga acerca del rol de las clases sociales, así como su evolución en el curso de los últimos decenios. Los autores entienden que las características individuales de los electores (ingresos, educación, confianza y bienestar) explican mejor el voto que las categorías socio-profesionales a las cuales pertenecen. Los autores abordan una serie de aspectos específicos (confianza, tradiciones religiosas y familiares) con el fin de analizar la formación de las ideologías de los electores, y su pertenencia política. Concluyen que la pertenencia a las grandes ideologías viene a ser reemplazada por representaciones políticas donde la subjetividad juega un rol más importante.

En el Capítulo IV, denominado “Tres grandes ideologías”, a partir de una distinción entre clivajes económicos y clivajes culturales, los autores dan cuenta de cuatro tipos de electores diferentes: electores liberales tanto en el plano socioeconómico como en el cultural (que apoyaron a Macron); conservadores en ambos aspectos (que dieron su apoyo a Le Pen); liberales en el plano cultural, no así en términos socioeconómicos (terreno de la izquierda tradicional); y conservadores en el plano cultural y liberales en términos económicos (derecha tradicional). Esto revela las tensiones internas entre los movimientos tradicionales que se suponían homogéneos. Abordan, así, el modo en el cual posturas contrarias se reactualizan dando lugar a nuevos paradigmas, todo ello a la luz de las ideologías culturales, que estipulan las relaciones con los Otros, de las ideologías económicas, que acarrean fundamentalmente las cuestiones acerca de la redistribución y el grado de intervención estatal, y de las instituciones políticas, que determinan la relación entre el Estado y las instituciones democráticas.

El Capítulo V, "El elector emocional", parte de la consideración de que las ideologías determinan los valores a partir de los cuales los votantes fijan su elección. Los autores afirman que el elector en tanto "ciudadano sentimental" se encuentra atravesado por un conjunto de emociones. En tanto el miedo rehúye hacia el conservadurismo, solo la "cólera", afirman, favorece las posturas más radicales. De allí que aquellos electores con pocos estudios, jóvenes, 
empobrecidos y desclasados que bien podrían optar por la abstención, se inclinan hacia la derecha populista. Esta actitud viene a ser matizada por la confianza interpersonal. Estar "enojado" con el sistema y disponer de un gran capital de confianza en las posibilidades de cambio orienta el voto hacia la izquierda radical; en tanto que la desconfianza en el "otro" resulta una mejor combinación emotivo-subjetiva para votar a favor de la "derecha populista".

En el Capítulo VI, "De Marchais à Le Pen", los autores sostienen que el quiebre dado entre las elecciones de 2012 y 2017 no es producto únicamente de las circunstancias personalísimas de tal o cual candidato, sino también de otro quiebre de mayor importancia, aquel del voto comunista. Las clases populares perdieron la fuerza política que les confería la sociedad industrial, transformándose paulatinamente en clases "infelices", constituidas por individuos aislados, presos de una sagaz desconfianza hacia la sociedad en su conjunto.

El Capítulo VII, "Les Gilets Jaunes", analiza la aparición de los "Chalecos Amarillos" en la escena política en otoño de 2018, a causa del aumento en el precio de los combustibles autorizados por el gobierno de Emmanuel Macron. La continuidad del movimiento, así como su composición social, animan a los autores a llevar a cabo un análisis de sus fortalezas y debilidades en vistas a comprender tanto la ideología antisistema como la recomposición del espectro político propiciada por la elección de Macron. La geografía de las protestas demuestra que no se trata únicamente de aquellos grupos pertenecientes a la "derecha populista", sino que se registra la presencia en igual magnitud de la "izquierda radical”, unidos por la caída de su poder adquisitivo. Ambos grupos descubren que, después de todo, su "padecimiento individual" es un "sufrimiento colectivo". A la luz de su análisis, los autores se preguntan: ¿es posible que dicho movimiento anuncie la formación de un frente antisistema? Tomando en cuenta la relación interpersonal que define a una y otra facción en base al binomio confianza-desconfianza, deducen que una alianza semejante difícilmente daría lugar a una programática extendida en el tiempo.

El Capítulo VIII, "Los populismos en Europa y Estados Unidos", analiza el modo en que, tanto en el continente europeo con en Estados Unidos ha habido un avance de las fuerzas antisistema, similar al caso francés. Los autores deducen que, salvo raras excepciones (Alemania), se encuentra el mismo esquema que en Francia, donde la radicalidad de las fuerzas antisistema se halla íntimamente ligada al malestar expuesto por sus reclamos. Las diversas investigaciones dan cuenta de una "inquietante degradación" de la confianza en el gobierno, el parlamento y la justicia en la mayor parte de las democracias occidentales en el curso de los últimos años. Esta degradación se ha visto acelerada por la crisis financiera, particularmente en Europa, donde los estados han sido incapaces de coordinar políticas económicas ambiciosas y han optado por políticas de austeridad, prolongando así los efectos dramáticos de la crisis.

De la posibilidad de creer en la capacidad de las autoridades públicas para regular los riesgos económicos y ambientales depende en gran parte la aptitud de las sociedades modernas para sobrellevar sus inquietudes y proporcionar respuestas. La inseguridad económica, exacerbada por la crisis financiera, la mundialización y la revolución 
tecnológica, ha acercado a los electores a los partidos "antisistema”.

El alza de las fuerzas antisistema decantó en dos flancos totalmente distintos del espectro político. Cada uno de estos campos ha roto los amarres que lo unían a sus antiguos aliados creando un sismo político que ha revolucionado la fisonomía de las pertenencias políticas. A pesar de un desdén compartido hacia las élites, las dos vertientes de protesta antisistema se apoyan en valores fundamentalmente opuestos.

La confianza interpersonal se revela como uno de los indicadores esen- ciales que permiten comprender la lógica de dicha divergencia programática. La confianza estructura aquello que designan implícitamente las ideologías: una manera de concebir el "vivir en conjunto".

Los autores concluyen que construir instituciones inclusivas, así como reinventar la vida política gracias a nuevas alianzas que reabran el debate democrático en lugar de cerrarlo en una oposición vana entre "la democracia y sus enemigos", es la tarea que el malestar que se expresa en el voto populista vuelve indispensable emprender. 